Article

\title{
Some New Observations on Geraghty and Ćirić Type Results in $b$-Metric Spaces
}

\author{
Nabil Mlaiki ${ }^{1, *}$, Neboǰ̌s Dedovic ${ }^{2}$, Hassen Aydi ${ }^{3,4, *}$, Milanka Gardašević-Filipović ${ }^{5}$, \\ Bandar Bin-Mohsin ${ }^{6}$ and Stojan Radenović ${ }^{6}$ \\ 1 Department of Mathematics and General Sciences, Prince Sultan University, Riyadh 11586, Saudi Arabia \\ 2 Faculty of Agriculture, University of Novi Sad, Trg Dositeja Obradovića 8, Novi Sad 21000, Serbia \\ 3 Institut Supérieur d'Informatique et des Techniques de Communication, Université de Sousse, \\ H. Sousse 4000, Tunisia \\ 4 China Medical University Hospital, China Medical University, Taichung 40402, Taiwan \\ 5 School of Computing, Union University, Belgrade 11000, Serbia \\ 6 Department of Mathematics, College of Science, King Saud University, Riyadh 11451, Saudi Arabia \\ * Correspondence: nmlaiki@psu.edu.sa (N.M.); hassen.aydi@isima.rnu.tn (H.A.)
}

Received: 10 June 2019; Accepted: 15 July 2019; Published: 18 July 2019

Abstract: We discuss recent fixed point results in $b$-metric spaces given by Pant and Panicker (2016). Our results are with shorter proofs. In addition, for $\varepsilon \in(1,3]$, our results are genuine generalizations of ones from Pant and Panicker.

Keywords: $(\Omega, \omega)$-admissible mappings; $b$-metric spaces; $b$-completeness; $b$-Cauchyness; generalized quasi-contraction

MSC: 47H10; 54H25

\section{Introduction}

We start with the following.

Definition $1([1,2])$. Let $f$ be a self-mapping on a metric space $(X, d)$. For $\mu \in X$, take

$$
O(\mu, n)=\left\{\mu, f \mu, \ldots, f^{n} \mu\right\} \text { and } O(\mu, \infty)=\left\{\mu, f \mu, \ldots, f^{n} \mu, \ldots\right\},
$$

where $n \in \mathbb{N}$. The set $O(\mu, \infty)$ is called an orbit of $f$. Such $(X, d)$ is said to be f-orbitally complete if each Cauchy sequence in $O(\mu, \infty)$ converges in $(X, d)$.

It is well known that every complete metric space is $f$-orbitally complete for each self-mapping $f$ on $X$. Its converse does not hold (see [1,2]).

Two very known and important generalizations of the Banach contraction principle [3] obtained by Ćirić [1] and Geraghty [4] as follows:

Theorem 1 ([1]). Let $(X, d)$ be an $f$-orbitally complete metric space and $f: X \rightarrow X$ be a quasi-contraction, i.e., there is $\lambda \in[0,1)$ so that

$$
d(f \mu, f \tau) \leq \lambda \cdot \max \{d(\mu, \tau), d(\mu, f \mu), d(\tau, f \tau), d(\mu, f \tau), d(f \mu, \tau)\},
$$

for all $\mu, \tau \in X$. Then, $f$ possesses a unique fixed point. 
Theorem 2 ([4]). Let $(X, d)$ be a complete metric space and $f: X \rightarrow X$ be such that

$$
d(f \mu, f \tau) \leq \beta(d(\mu, \tau)) d(\mu, \tau)
$$

for all $\mu, \tau \in X$, where $\beta:[0, \infty) \rightarrow[0,1)$ is such that $\beta\left(t_{n}\right) \rightarrow 1$ implies $t_{n} \rightarrow 0$ as $n \rightarrow \infty$. Then, $f$ has a unique fixed point.

The concept of quasi-contractions has been generalized by Kumam et al. [2].

Definition 2 ([2]). A self-mapping $f$ on a metric space $(X, d)$ is called a generalized quasi-contraction if there is $\lambda \in[0,1)$ so that

$$
d(T \mu, T \tau) \leq \lambda \cdot M(\mu, \tau)
$$

for all $\mu, \tau \in X$, where

$$
M(\mu, \tau)=\max \left\{d(\mu, \tau), d(\mu, f \mu), d(\tau, f \tau), d(\mu, f \tau), d(f \mu, \tau), d\left(f^{2} \mu, \mu\right), d\left(f^{2} \mu, f \mu\right), d\left(f^{2} \mu, \tau\right), d\left(f^{2} \mu, f \tau\right)\right\} .
$$

Theorem 3 ([2]). Each generalized quasi-contraction self-mapping $f$ on an $f$-orbitally complete metric space admits a unique fixed point.

Given $s \geq 1$. A function $d: X \times X \rightarrow[0, \infty)$ is called a $b$-metric on a non-empty set $X$ if for all $\mu, \tau, \xi \in X, d(\mu, \tau)=0$ iff $\mu=\tau, d(\mu, \tau)=d(\tau, \mu)$ and $d(\mu, \xi) \leq s[d(\mu, \tau)+d(\tau, \xi)]$. The concept of $b$-convergence, $b$-completeness, $b$-Cauchyness in $b$-metric spaces can be found in [5-38].

Definition 3 ([39]). Given $\Omega: X \times X \rightarrow[0, \infty)$ and $f: X \rightarrow X$, such $f$ is called $\Omega$-admissible if, for all $\mu, \tau \in X$,

$$
\Omega(\mu, \tau) \geq 1 \text { implies } \Omega(f \mu, f \tau) \geq 1 \text {. }
$$

Definition 4 ([40]). The mapping $f: X \rightarrow X$ is called triangular $\Omega$-admissible if for all $\mu, \tau, \xi \in X$,

(i) $\Omega(\mu, \tau) \geq 1$ implies $\Omega(f \mu, f \tau) \geq 1$;

(ii) $\Omega(\mu, \xi) \geq 1$ and $\Omega(\xi, \tau) \geq 1$ implies $\Omega(\mu, \tau) \geq 1$.

Lemma 1 ([40]). Let $f$ be a triangular $\Omega$-admissible mapping. Suppose there is $\mu_{0} \in X$ so that $\Omega\left(\mu_{0}, f \mu_{0}\right) \geq 1$. Define $\left\{\mu_{n}\right\}$ by $\mu_{n}=f^{n} \mu_{0}$. Then, $\Omega\left(\mu_{m}, \mu_{n}\right) \geq 1$ for all $m, n \in \mathbb{N}$ with $m<n$.

Very recently, Pant and Panciker [35] initiated the concept of generalized $\Omega$-quasi-contraction in $b$-metric spaces. Namely, they defined and proved the following:

Definition 5 ([35]). Let $(X, d)$ be a b-metric space with constant $s \geq 1$. The self-mapping $f$ on $X$ is called a generalized $\Omega$-quasi-contraction if there are $\Omega: X \times X \rightarrow[0, \infty)$ and a real number $q$ with $0<q<\frac{1}{s^{2}}$ such that

$$
\Omega(\mu, \tau) d(f \mu, f \tau) \leq q M(\mu, \tau)
$$

where $M(\mu, \tau)$ is given by (4).

Lemma 2 ([35]). Let $(X, d)$ be a b-metric space with $s \geq 1$ and $f: X \rightarrow X$ be a generalized $\Omega$-quasi contraction such that

(A): $f$ is triangular $\Omega$-admissible;

(B): there is $\mu_{0} \in X$ so that $\Omega\left(\mu_{0}, f \mu_{0}\right) \geq 1$.

Then, for all $p, k \in\{1,2, \ldots, n\}$ with $(p<k)$, we have

$$
d\left(f^{p} \mu_{0}, f^{k} \mu_{0}\right) \leq q \delta\left[O\left(\mu_{0}, n\right)\right]
$$


Theorem 4 ([35]). Let $(X, d)$ be a f-orbitally complete b-metric space with $s \geq 1$ and $f: X \rightarrow X$ be a generalized $\Omega$-quasi-contraction so that $(\boldsymbol{A})$ and $(\boldsymbol{B})$ of Lemma 2 hold. Then, $f$ admits a fixed point.

The proofs of Lemma 2 and Theorem 4 are based on Lemma 1.

Motivated by Ćirić [1], Geraghty [4], Kumam et al. [2], Samet et al. [39] as well as Pant and Panciker [35], we improve some related fixed point theorems in $b$-metric spaces. Our proofs are much shorter and nicer than the ones in [35].

Corollary 1. Let $(X, d)$ be a $b$-complete b-metric space with a constant $s \geq 1$. Given $\Omega: X \times X \rightarrow[0, \infty) a$ functional, let $f: X \rightarrow X$ be an $\Omega$-quasi-contraction, i.e.,

$$
\Omega(\mu, \tau) d(f \mu, f \tau) \leq q \cdot m(\mu, \tau),
$$

for all $\mu, \tau \in X$, where $0 \leq q<1$ and $m(\mu, \tau)=\max \{d(\mu, \tau), d(\mu, f \mu), d(\tau, f \tau), d(\mu, f \tau), d(f \mu, \tau)\}$. Suppose that

(i) $f$ is $\Omega$-admissible;

(ii) there is $\mu_{0} \in X$ so that $\Omega\left(\mu_{0}, f \mu_{0}\right) \geq 1$.

If $q<\frac{1}{s^{2}+s}$, then $f$ admits a fixed point.

Chandok [41] defined the following.

Definition 6 ([41]). Let $(X, d)$ be a b-metric space with constant $s \geq 1, f: X \rightarrow X$ and $\Omega, \omega: X \times$ $X \rightarrow[0, \infty)$. The mapping $f$ is said to be $(\Omega, \omega)$-admissible if $\Omega(\mu, \tau) \geq 1$ and $\omega(\mu, \tau) \geq 1$ implies $\Omega(f \mu, f \tau) \geq 1$ and $\omega(f \mu, f \tau) \geq 1$ for all $\mu, \tau \in X$.

Definition 7 ([41]). Let $\Omega, \omega: X \times X \rightarrow[0, \infty)$. A b-metric space $(X, d)$ with a constant $s \geq 1$ is $(\Omega, \omega)$-regular if $\left\{\mu_{n}\right\}$ is a sequence in $X$ such that $\mu_{n} \rightarrow x \in X, \Omega\left(\mu_{n}, \mu_{n+1}\right) \geq 1, \omega\left(\mu_{n}, \mu_{n+1}\right) \geq 1$, for all $n$; then, there is a subsequence $\left\{\mu_{n_{k}}\right\}$ of $\left\{\mu_{n}\right\}$ such that $\Omega\left(\mu_{n_{k}}, \mu_{n_{k}+1}\right) \geq 1, \omega\left(\mu_{n_{k}}, \mu_{n_{k}+1}\right) \geq 1$, for all $k \in \mathbb{N}$ and $\Omega(\mu, f \mu) \geq 1, \omega(\mu, f \mu) \geq 1$.

The two following classes of functions are defined in [35].

(1) $\Theta$ denotes the family of functions $\theta:[0, \infty) \rightarrow[0,1)$ so that, for any bounded sequence $\left\{t_{n}\right\}$ of positive reals, $\theta\left(t_{n}\right) \rightarrow 1$ implies $t_{n} \rightarrow 0$;

(2) $\Psi$ denotes the set of functions $\psi:[0, \infty) \rightarrow[0, \infty)$ so that $\psi$ is continuous, strictly increasing and $\psi(0)=0$.

Definition 8 ([35]). Let $(X, d)$ be a b-metric space with constant $s \geq 1$. The mapping $f: X \rightarrow X$ is called an $(\Omega, \omega)$-Geraghty type contraction if there are $\theta \in \Theta, \psi \in \Psi$ and $\Omega, \omega: X \times X \rightarrow[0, \infty)$ such that

$$
\Omega(\mu, f \mu) \omega(\tau, f \tau) \psi\left(s^{3} d(f \mu, f \tau)\right) \leq \theta(\psi(N(\mu, \tau))) \psi(N(\mu, \tau)),
$$

for all $\mu, \tau \in X$, where $N(\mu, \tau)=\max \left\{d(\mu, \tau), d(\mu, f \mu), d(\tau, f \tau), \frac{d(\mu, f \tau)+d(\tau, f \mu)}{2 s}\right\}$.

Theorem 5 ([35]). Let $(X, d)$ be a b-complete b-metric space with a constant $s \geq 1$ and $f: X \rightarrow X$ be $a$ self-mapping. Suppose that the following assertions hold:

$(\boldsymbol{A}): f$ is $(\Omega, \omega)$-admissible;

(B): $f$ is an $(\Omega, \omega)$-Geraghty type contraction;

(C): there is $\mu_{0} \in X$ so that $\Omega\left(\mu_{0}, f \mu_{0}\right) \geq 1$ and $\omega\left(\mu_{0}, f \mu_{0}\right) \geq 1$;

(D): either $f$ is continuous, or $(X, d)$ is $(\Omega, \omega)$-regular.

Then, $f$ has a unique fixed point. 
Corollary 2 ([35]). Let $(X, d)$ be a b-complete b-metric space with $s \geq 1$ and $f: X \rightarrow X$ be a self-mapping. Suppose that the following assertions hold:
(A): $f$ is $\Omega$-admissible;
(B): $f$ is an $\Omega$-Geraghty type contraction;
(C): there is $\mu_{0} \in X$ so that $\Omega\left(\mu_{0}, f \mu_{0}\right) \geq 1$;
(D): either $f$ is continuous or $(X, d)$ is $\Omega$-regular.
Then, $f$ admits a unique fixed point.

The proofs of Theorem 5 (and Corollary 2) are based on the following crucial lemma.

Lemma 3 ([8]). Let $(X, d)$ be a b-metric space with $s \geq 1$. Let $\left\{\mu_{n}\right\}$ and $\left\{\tau_{n}\right\}$ b-converge to $\mu, \tau \in X$, respectively. We have

$$
\frac{1}{s^{2}} d(\mu, \tau) \leq \liminf _{n \rightarrow \infty} d\left(\mu_{n}, \tau_{n}\right) \leq \limsup _{n \rightarrow \infty} d\left(\mu_{n}, \tau_{n}\right) \leq s^{2} d(\mu, \tau) .
$$

In particular, if $\mu=\tau$, then $\lim _{n \rightarrow \infty} d\left(\mu_{n}, \tau_{n}\right)=0$. In addition, for any $\xi \in X$,

$$
\frac{1}{s} d(\mu, \xi) \leq \liminf _{n \rightarrow \infty} d\left(\mu_{n}, \xi\right) \leq \limsup _{n \rightarrow \infty} d\left(\mu_{n}, \xi\right) \leq s d(\mu, \xi)
$$

\section{Main Results}

Instead of Lemma 3, we will use in this paper the next result to establish our main results.

Lemma 4. ([28], Lemma 3.1) Let $\left\{\mu_{n}\right\}$ be a sequence in a $b$-metric space $(X, d, s \geq 1)$ such that

$$
d\left(\mu_{n+1}, \mu_{n+2}\right) \leq \lambda d\left(\mu_{n}, \mu_{n+1}\right), n \geq 0,
$$

for some $\lambda \in\left[0, \frac{1}{s}\right)$. Then, $\left\{\mu_{n}\right\}$ is a $b$-Cauchy sequence in $X$.

By Lemma 4, it would be good to note that each Picard sequence is $b$-Cauchy, and so the proofs of some results (such as, the ones in the sequel) become shorter.

Remark 1. In many results based on b-metric spaces with a constant $s \geq 1$, people often suppose that $\lambda \in\left[0, \frac{1}{s}\right)$ instead of $\lambda \in[0,1)$, which is clearly a stronger condition due to the fact that $\left[0, \frac{1}{s}\right) \subseteq[0,1)$. To ensure this fact, the following inequality is utilized:

$$
d\left(\mu_{m}, \mu_{n}\right) \leq s d\left(\mu_{m}, \mu_{m+1}\right)+s^{2} d\left(\mu_{m+1}, \mu_{m+2}\right)+\cdots+s^{n-m-1} d\left(\mu_{n-2}, \mu_{n-1}\right)+s^{n-m-1} d\left(\mu_{n-1}, \mu_{n}\right),
$$

for $n, m \in \mathbb{N}$ and $n>m$.

Since there is a doubt in the proof of Theorem 3.5 of [35] (see [35], page 6, line 13: about the inequality: $\left.d\left(T u, T T^{n} \mu_{0}\right) \leq \Omega\left(u, T^{n} \mu_{0}\right) d\left(T u, T T^{n} \mu_{0}\right)\right)$, we give the following new result.

Theorem 6. Let $(X, d)$ be an $f$-orbitally b-complete b-metric space (with $s>1$ ) and let $f: X \rightarrow X$ be $a$ generalized $\Omega$-quasi-contraction where $(\boldsymbol{A})$ and $(\boldsymbol{B})$ of Lemma 2 both hold. If either $f$ is continuous, or $(X, d)$ is $\Omega$-regular, then $f$ possesses a fixed point. 
Proof. By assumption, there is $\mu_{0} \in X$ so that $\Omega\left(\mu_{0}, f \mu_{0}\right) \geq 1$. We will show that the sequence $\left\{\mu_{n}=f^{n} \mu_{0}\right\}_{n \in \mathbb{N}}$ is $b$-Cauchy in the $b$-metric space $(X, d)$. Indeed, let $\mu_{n} \neq \mu_{n-1}$ for all $n \in \mathbb{N}$. According to (A) from Lemma 2, it follows that $\Omega\left(\mu_{n}, \mu_{n+1}\right) \geq 1$ for each $n \geq 0$. Therefore,

$$
d\left(\mu_{n+1}, \mu_{n+2}\right) \leq \Omega\left(\mu_{n}, \mu_{n+1}\right) d\left(f \mu_{n}, f \mu_{n+1}\right) \leq q M\left(\mu_{n}, \mu_{n+1}\right)
$$

where

$$
\begin{aligned}
M\left(\mu_{n}, \mu_{n+1}\right) & =\max \left\{d\left(\mu_{n}, \mu_{n+1}\right), d\left(\mu_{n+1}, \mu_{n+2}\right), d\left(\mu_{n}, \mu_{n+2}\right)\right\} \\
& \leq \max \left\{d\left(\mu_{n}, \mu_{n+1}\right), d\left(\mu_{n+1}, \mu_{n+2}\right), s\left(d\left(\mu_{n}, \mu_{n+1}\right)+d\left(\mu_{n+1}, \mu_{n+2}\right)\right)\right\} \\
& =s\left(d\left(\mu_{n}, \mu_{n+1}\right)+d\left(\mu_{n+1}, \mu_{n+2}\right)\right) .
\end{aligned}
$$

Hence,

$$
d\left(\mu_{n+1}, \mu_{n+2}\right) \leq \frac{q s}{1-q s} d\left(\mu_{n}, \mu_{n+1}\right)=\lambda d\left(\mu_{n}, \mu_{n+1}\right)
$$

where $\lambda=\frac{q s}{1-q s}<\frac{1}{s}$ because $q<\frac{1}{s^{2}}$.

Now, by ([28], Lemma 3.1), the sequence $\left\{\mu_{n}=f^{n} \mu_{0}\right\}$ is $b$-Cauchy. Since $(X, d)$ is $f$-orbitally $b$-complete, there is $u \in X$ so that $\lim _{n \rightarrow \infty} f^{n} \mu_{0}=u$. If $f$ is continuous, then obviously $f u=u$. When $(X, d)$ is $\Omega$-regular, we have (because $\Omega\left(u, \mu_{n}\right) \geq 1$ )

$$
\begin{aligned}
\frac{1}{s} d(u, f u) & \leq d\left(u, \mu_{n+1}\right)+d\left(f \mu_{n}, f u\right) \\
& \leq d\left(u, \mu_{n+1}\right)+\Omega\left(u, \mu_{n}\right) d\left(f \mu_{n}, f u\right) \\
& \leq d\left(u, \mu_{n+1}\right)+q M\left(\mu_{n}, u\right)
\end{aligned}
$$

where

$$
\begin{aligned}
M\left(\mu_{n}, u\right)= & \max \left\{d\left(\mu_{n}, u\right), d\left(\mu_{n}, \mu_{n+1}\right), d(u, f u), d\left(\mu_{n}, f u\right), d\left(u, \mu_{n+1}\right), d\left(\mu_{n+2}, u\right),\right. \\
& \left.d\left(\mu_{n+2}, \mu_{n+1}\right), d\left(\mu_{n+2}, u\right), d\left(\mu_{n+2}, f u\right)\right\} .
\end{aligned}
$$

Furthermore,

$$
\begin{aligned}
M\left(\mu_{n}, u\right) \leq & \max \left\{d\left(\mu_{n}, u\right), d\left(\mu_{n}, \mu_{n+1}\right), d(u, f u), s\left(d\left(\mu_{n}, u\right)+d(u, f u)\right), d\left(u, \mu_{n+1}\right), d\left(\mu_{n+2}, u\right),\right. \\
& \left.d\left(\mu_{n+2}, \mu_{n+1}\right), d\left(\mu_{n+2}, u\right), s\left(d\left(\mu_{n+2}, u\right)+d(u, f u)\right)\right\} \\
\rightarrow & \max \{0,0, d(u, f u), s d(u, f u), 0,0,0,0, s d(u, f u)\} \\
= & s d(u, f u)
\end{aligned}
$$

as $n \rightarrow \infty$.

Hence,

$$
\frac{1}{s} d(u, f u) \leq s q d(u, f u) \text { or equivalently } \frac{1}{s^{2}} d(u, f u) \leq q d(u, f u),
$$

which is possible only if $f u=u$.

Remark 2. If $q<\frac{1}{s^{2}}$, then our approach gives a short and nice proof that a generalized $\Omega$-quasi-contraction $f: X \rightarrow X$ has a fixed point. However, the proof of the corresponding result in ([35], page 6, line 13+) is not correct without the assumption that the $b$-metric space $(X, d)$ is $\Omega$-regular. This new compliment of the proof of Theorem 3.5 in [35] is correct if $q<\frac{1}{s^{2}}$.

We introduce the following. 
Definition 9. Let $(X, d, s>1)$ be a b-metric space. The mapping $f: X \rightarrow X$ is said to be an $(\Omega, \omega)$-type contraction if there are $\Omega, \omega: X \times X \rightarrow[0, \infty), \varepsilon>1$ and $\psi \in \Psi$ such that

$$
\Omega(\mu, f \mu) \omega(\tau, f \tau) \psi\left(s^{\varepsilon} d(f \mu, f \tau)\right) \leq \psi(N(\mu, \tau)),
$$

for all $\mu, \tau \in X$, where $N(\mu, \tau)=\max \left\{d(\mu, \tau), d(\mu, f \mu), d(\tau, f \tau), \frac{d(\mu, f \tau)+d(\tau, f \mu)}{2 s}\right\}$.

Remark 3. The contraction (14) generalizes the corresponding ones from ([35], Definition 4.3) in several directions.

Now, we can prove the next result.

Theorem 7. Let $(X, d, s>1)$ be a b-complete b-metric space, $f: X \rightarrow X$, and $\Omega, \omega: X \times X \rightarrow[0, \infty)$. Suppose that the following assertions hold:
(A) $f$ is $(\Omega, \omega)$-admissible;
(B) $f$ is an $(\Omega, \omega)$-contraction;
(C) there is $\mu_{0} \in X$ so that $\Omega\left(\mu_{0}, f \mu_{0}\right) \geq 1$ and $\omega\left(\mu_{0}, f \mu_{0}\right) \geq 1$;
(D) either $f$ is continuous or $(X, d, s>1)$ is $(\Omega, \omega)$-regular.

Then, $f$ has a unique fixed point.

Proof. As in [35], page 5748, we get

$$
\begin{aligned}
\psi\left(d\left(\mu_{n+1}, \mu_{n+2}\right)\right) & =\psi\left(d\left(f \mu_{n}, f \mu_{n+1}\right)\right) \\
& \leq \psi\left(s^{\varepsilon} d\left(f \mu_{n}, f \mu_{n+1}\right)\right) \\
& \leq \Omega\left(\mu_{n}, f \mu_{n}\right) \omega\left(\mu_{n+1}, f \mu_{n+1}\right) \psi\left(s^{\varepsilon} d\left(f \mu_{n}, f \mu_{n+1}\right)\right) \\
& \leq \psi\left(N\left(\mu_{n}, \mu_{n+1}\right)\right),
\end{aligned}
$$

or equivalently, $s^{\varepsilon} d\left(f \mu_{n}, f \mu_{n+1}\right) \leq N\left(\mu_{n}, \mu_{n+1}\right)$, where

$$
\begin{aligned}
N\left(\mu_{n}, \mu_{n+1}\right) & =\max \left\{d\left(\mu_{n}, \mu_{n+1}\right), d\left(\mu_{n+1}, \mu_{n+2}\right), \frac{d\left(\mu_{n}, \mu_{n+2}\right)}{2 s}\right\} \\
& \leq \max \left\{d\left(\mu_{n}, \mu_{n+1}\right), d\left(\mu_{n+1}, \mu_{n+2}\right), \frac{d\left(\mu_{n}, \mu_{n+1}\right)+d\left(\mu_{n+1}, \mu_{n+2}\right)}{2}\right\} \\
& \leq \max \left\{d\left(\mu_{n}, \mu_{n+1}\right), d\left(\mu_{n+1}, \mu_{n+2}\right)\right\} \\
& \leq N\left(\mu_{n}, \mu_{n+1}\right) .
\end{aligned}
$$

Hence, $s^{\varepsilon} d\left(f \mu_{n}, f \mu_{n+1}\right) \leq \max \left\{d\left(\mu_{n}, \mu_{n+1}\right), d\left(\mu_{n+1}, \mu_{n+2}\right)\right\}$.

It is not hard to see that $s^{\varepsilon} d\left(f \mu_{n}, f \mu_{n+1}\right) \leq d\left(\mu_{n}, \mu_{n+1}\right)$. That is,

$$
d\left(\mu_{n+1}, \mu_{n+2}\right) \leq \frac{1}{s^{\varepsilon}} d\left(\mu_{n}, \mu_{n+1}\right)=\lambda d\left(\mu_{n}, \mu_{n+1}\right)
$$

where $\lambda=\frac{1}{s^{\varepsilon}}<\frac{1}{s}$.

As in the proof of Theorem 6 , the sequence $\left\{\mu_{n}=f^{n} \mu_{0}\right\}$ is $b$-Cauchy in $b$-complete $b$-metric space, so there is $u \in X$ so that $\mu_{n} \rightarrow u$ as $n \rightarrow \infty$. In the case that $f$ is continuous, one writes

$$
u=\lim _{n \rightarrow \infty} \mu_{n+1}=\lim _{n \rightarrow \infty} f \mu_{n}=f\left(\lim _{n \rightarrow \infty} \mu_{n}\right)=f u .
$$


In the case that $(X, d)$ is $(\Omega, \omega)$-regular, there is $\left\{\mu_{n_{k}}\right\}$ of $\left\{\mu_{n}\right\}$ so that $\Omega\left(\mu_{n_{k}+1}, \mu_{n_{k}}\right) \geq 1$ and $\omega\left(\mu_{n_{k}+1}, \mu_{n_{k}}\right) \geq 1$ for all $k \in \mathbb{N}$ and $\Omega(u, f u) \geq 1$ and $\omega(u, f u) \geq 1$. Using Equation (14) with $\mu=\mu_{n_{k}}$ and $\tau=u$, we have

$$
\begin{aligned}
\psi\left(s^{\varepsilon} d\left(f \mu_{n_{k}}, f u\right)\right) & \leq \Omega\left(\mu_{n_{k}} f \mu_{n_{k}}\right) \omega(u, f u) \psi\left(s^{\varepsilon} d\left(f \mu_{n_{k}}, f u\right)\right) \\
& \leq \psi\left(N\left(\mu_{n_{k}}, u\right)\right) .
\end{aligned}
$$

Consequently, $s^{\varepsilon} d\left(f \mu_{n_{k}}, f u\right) \leq N\left(\mu_{n_{k}}, u\right)$, where

$$
\begin{aligned}
N\left(\mu_{n_{k}}, u\right) & =\max \left\{d\left(\mu_{n_{k}}, u\right), d\left(\mu_{n_{k}}, f \mu_{n_{k}}\right), d(u, f u), \frac{d\left(\mu_{n_{k}}, f u\right)+d\left(f \mu_{n_{k}}, u\right)}{2 s}\right\} \\
& =\max \left\{d\left(\mu_{n_{k}}, u\right), d\left(\mu_{n_{k}}, \mu_{n_{k}+1}\right), d(u, f u), \frac{d\left(\mu_{n_{k}}, f u\right)+d\left(\mu_{n_{k}+1}, u\right)}{2 s}\right\} .
\end{aligned}
$$

Since $\frac{1}{s} d\left(\mu_{n_{k}}, f u\right) \leq d\left(\mu_{n_{k}}, u\right)+d(u, f u)$, we get $N\left(\mu_{n_{k}}, u\right) \rightarrow d(u, f u)$ as $k \rightarrow \infty$

On the other hand,

$$
\frac{1}{s} d(u, f u) \leq d\left(u, \mu_{n_{k}+1}\right)+d\left(f \mu_{n_{k}}, f u\right),
$$

that is,

$$
\frac{1}{s} d(u, f u) \leq d\left(u, \mu_{n_{k}+1}\right)+\frac{1}{s^{\varepsilon}} \max \left\{d\left(\mu_{n_{k}}, u\right), d\left(\mu_{n_{k}}, \mu_{n_{k}+1}\right), d(u, f u), \frac{d\left(\mu_{n_{k}}, f u\right)+d\left(\mu_{n_{k}+1}, u\right)}{2 s}\right\},
$$

i.e., $\frac{1}{s} d(u, f u) \leq \frac{1}{s^{\varepsilon}} d(u, f u)$. Since $\varepsilon>1$, the last inequality holds unless $u=f u$.

Now, suppose $v$ is so that $f u=u \neq v=f v$. Putting $\mu=u$ and $\tau=v$ in (14),

$$
\psi\left(s^{\varepsilon} d(u, v)\right) \leq \Omega(u, f u) \omega(v, f v) \psi\left(s^{\varepsilon} d(u, v)\right) \leq \psi(N(u, v)),
$$

where

$$
\begin{aligned}
N(u, v) & =\max \left\{d(u, v), d(u, f u), d(v, f v), \frac{d(u, f v)+d(v, f u)}{2 s}\right\} \\
& =\max \left\{d(u, v), 0,0, \frac{d(u, v)}{s}\right\} \\
& =d(u, v) .
\end{aligned}
$$

Hence, $\psi\left(s^{\varepsilon} d(u, v)\right) \leq \psi(d(u, v))$ is possible only if $u=v$. The proof of the result is finished.

Remark 4. It is not hard to check that Example 4.6 from [35] satisfies all conditions of Theorem 7 for $\varepsilon \in(1,3]$. Indeed, since for all $x, y \in X$ and for all $\varepsilon \in(1,3]$, it follows that

$$
\begin{aligned}
\alpha(x, y) \beta(x, y) \psi\left(s^{\varepsilon} d(T x, T y)\right) & \leq \alpha(x, y) \beta(x, y) \psi\left(s^{3} d(T x, T y)\right) \\
& \leq \theta(\psi(N(x, y))) \psi(N(x, y)) .
\end{aligned}
$$

That is,

$$
\alpha(x, y) \beta(x, y) \psi\left(s^{\varepsilon} d(T x, T y)\right) \leq \theta(\psi(N(x, y))) \psi(N(x, y)),
$$

for all $x, y \in X$ and for all $\varepsilon \in(1,3]$. This means that Example 4.6. from [35] supports Theorem 7. On the other hand, Theorem 7 extends the main result from [35] of $\{\varepsilon=3\}$ to $\varepsilon \in(1,3]$. Thus, our results are genuine generalizations of ones from [35]. 
In [30], the authors introduced so-called Geraghty type functions. Denote by $\Psi$ the set of continuous increasing nonnegative functions $\psi$ defined on $[0, \infty)$ so that $\psi^{-1}(0)=\{0\}$. Take $s \geq 1$. Let $\mathcal{F}$ be the family of all nondecreasing functions $\beta:[0, \infty) \rightarrow\left[0, \frac{1}{s}\right)$ so that

$$
\lim _{k \infty} \beta\left(l_{k}\right)=\frac{1}{s} \text { implies } \lim _{k \rightarrow \infty} l_{k}=0 .
$$

Definition 10. Let $T$ be a self-mapping on a b-metric space $(M, d)$. $T$ is a generalized $\Omega-\psi$-Geraghty contractive mapping if there are $\Omega: M \times M \rightarrow[0, \infty), \beta \in \mathcal{F}, \psi, \phi \in \Psi$ and $L \geq 0$ so that for

$$
E(\mu, \tau)=\max \left\{d(\mu, \tau), d(\mu, T \mu), d(\tau, T \tau), \frac{d(\mu, T \tau)+d(\tau, T \mu)}{2 s}\right\}
$$

and

$$
N(\mu, \tau)=\min \{d(\mu, T \mu), d(\tau, T \tau)\}
$$

we have

$$
\Omega(\mu, \tau) \psi\left(s^{3} d(T \mu, T \tau)\right) \leq \beta(E(\mu, \tau)) \psi(E(\mu, \tau))+L \phi(N(\mu, \tau)),
$$

for all $\mu, \tau \in M$.

Theorem 8. Let $(M, d, s \geq 1)$ be a b-complete b-metric space and $T: M \rightarrow M$ be a generalized $\Omega-$ $\psi$-Geraghty contraction so that

(i) $T$ is triangular $\Omega$-orbital admissible;

(ii) there is $\mu_{0} \in M$ so that $\Omega\left(\mu_{0}, T \mu_{0}\right) \geq 1$;

(iii) $T$ is continuous.

Then, $T$ has a fixed point.

Note that for the proof of the announced result in [30], the authors used Lemma 3. However, our approach does not require this lemma and the proof is much shorter. Namely, we consider the following:

$$
\Omega(\mu, \tau) \psi\left(s^{\varepsilon} d(T \mu, T \tau)\right) \leq \beta(E(\mu, \tau)) \psi(E(\mu, \tau))+L \phi(N(\mu, \tau)),
$$

where $\varepsilon>1$, instead Equation (15). On the other hand,

$$
d\left(\mu_{n+1}, \mu_{n}\right) \leq \frac{1}{s^{\varepsilon}} d\left(\mu_{n}, \mu_{n-1}\right), \quad n \geq 1 .
$$

This further implies that the sequence $\left\{\mu_{n}\right\}$ is $b$-Cauchy. The proof is now similar to its corresponding one in [30].

Remark 5. Since $\beta([0, \infty)) \subseteq[0,1)$, it is not hard to see that Equation (14) becomes

$$
\Omega(\mu, \tau) \psi\left(s^{3} d(T \mu, T \tau)\right) \leq \psi(E(\mu, \tau))+L \phi(N(\mu, \tau),
$$

that is, the Geraghty type case in b-metric spaces is superfluous.

It is worth mentioning the following:

Theorem 3 is a consequence of an old theorem of Hegedus [26]. In addition, Ćirićs Definition of quasi-contractions and Definition 2 are special cases of the following Definition of Hegedus [26]. 
Definition 11 ([26]). A self-mapping $T$ on a metric space $X$ is called a generalized Banach contraction if, for all $x, y \in X, \delta(x, y)<\infty$ and $d(T x, T y) \leq \lambda \delta(x, y)$ for some $\lambda<1$, where $\delta(x, y)=\operatorname{diam}[O(x, \infty) \cup O(y, \infty)]$.

Furthermore, Theorem 1 and Theorem 3 are special cases of the following theorem of Hegedus [26] (by omitting the approximation part of the theorem).

Theorem 9 ([26]). Every generalized Banach contraction on a T-orbitally complete metric space has a unique fixed point.

\section{Conclusions}

This paper contains much shorter and more elementary proof of ones given in existing literature for some mappings in the context of b-metric spaces.

Author Contributions: After announced the paper [35], second, fourth, fifth and sixth authors initiated research and proved some results After that, first and third authors proved other theorems. Otherwise, all authors read and approved the final manuscript.

Funding: This research received no external funding.

Acknowledgments: The first author would like to thank Prince Sultan University for funding this work through research group Nonlinear Analysis Methods in Applied Mathematics (NAMAM) group number RG-DES-2017-01-17. The second author is thakful for the Ministry of Education, Science and Technological Development of Serbia TR31046. The fifth and sixth authors are pleased to acknowledge the support of the "Distinguished Scientist Fellowship".

Conflicts of Interest: The authors declare that they have no competing interests regarding the publication of this paper.

\section{References}

1. Ćirić, L. A generalization of Banach's contraction principle. Proc. Am. Math. Soc. 1974, 45, 267-273. [CrossRef]

2. Kumam, P.; Dung, N.V.; Sitytithakerngkiet, K. A generalization of Ćirić fixed point theorems. Filomat 2015, 29, 1549-1556. [CrossRef]

3. Banach, S. Sur les opérations dans les ensembles abstraits et leur application aux équations intégrales. Fundam. Math. 1922, 3, 133-181. [CrossRef]

4. Geraghty, M. On contraction mappings. Proc. Am. Math. Soc. 1973, 40, 604-608. [CrossRef]

5. Czerwik, S. Contraction mappings in B-Metr. Spaces. Acta Math. Inform. Univ. Ostrav. 1993, 1, 5-11.

6. Afshari, H.; Aydi, H.; Karapinar, E. On generalized $\alpha-\psi$-Geraghty contractions on $b$-metric spaces. Georgian Math. J. 2018. [CrossRef]

7. Afshari, H.; Atapour, M.; Aydi, H. Generalized $\alpha-\psi$-Geraghty multivalued mappings on $b$-metric spaces endowed with a graph. TWMS J. Appl. Eng. Math. 2017, 7, 248-260.

8. Aghajani, A.; Abbas, M.; Roshan, J.R. Common fixed point of generalized weak contractive mappings in partially ordered $b$-metric spaces. Math. Slovaca 2014, 4, 941-960.

9. Aleksić, S.; Huang, H.; Mitrović, Z.D.; Radenović, S. Remarks on some fixed point results in $b$-metric spaces. J. Fixed Poiunt Theory Appl. 2018, 20, 147. [CrossRef]

10. Aleksić, S.; Mitrović, Z.D.; Radenović, S. On some recent fixed point results for single and multi-valued mappings in b-metric spaces. Fasc. Math. 2018, 61, 5-16.

11. Aleksić, S.; Došenović, T.; Mitrović, Z.D.; Radenović, S. Remarks on common fixed point results for generalized $\alpha_{*}-\psi$-contraction multivalued mappings in $b$-metric spaces. Adv. Fixed Point Theory 2018, 9, 1-16.

12. Amini-Harandi, A. Fixed point theory for quasi-contraction maps in b-metric spaces. Fixed Point Theory 2014, 15, 351-358.

13. Aydi, H.; Bota, M.F.; Karapinar, E.; Moradi, S. A common fixed point for weak $\phi$-contractions on $b$-metric spaces. Fixed Point Theory 2012, 13, 337-346.

14. Aydi, H.; Karapinar, E.; Bota, M.F.; Mitrović, S. A fixed point theorem for set-valued quasi-contractions in b-metric spaces. Fixed Point Theory Appl. 2012, 2012, 88. [CrossRef] 
15. Aydi, H.; Felhi, A.; Sahmim, S. Common fixed points via implicit contractions on $b$-metric-like spaces. J. Nonlinear Sci. Appl. 2017, 10, 1524-1537. [CrossRef]

16. Aydi, H.; Banković, R.; Mitrović, I.; Nazam, M. Nemytzki-Edelstein-Meir-Keeler type results in $b$-metric spaces. Discrete Dyn. Nat. Soc. 2018, 2018, 4745764. [CrossRef]

17. Bakhtin, I.A. The contraction principle in quasimetric spaces. Funct. Anal. 1989, 30, $26-37$.

18. Chandok, S.; Jovanović, M.; Radenović, S. Ordered $b$-metric spaes and Geraghty type contractive mappings. Vojnoteh. Glas. Tech. Cour. 2017, 65, 331-345. [CrossRef]

19. Chandok, S.; Huaping, H.; Radenović, S. Some fixed point results for generalized F-Suzuki type contractions in $b$-metric spaces. Sahand Commun. Math. Anal. 2018, 11, 81-89.

20. Chandok, S.; Radenović, S.; Ozturk, V. Some fixed point results in the framework of $b$-metric spaces. Mat. Vesnik. 2019, 71, 23-30.

21. Ding, H.S.; Imdad, M.; Radenović, S.; Vujaković, J. On some fixed point results in $b$-metric, rectangular and b-rectangular metric spaces. Arab J. Math. Sci. 2015. [CrossRef]

22. Došenović, T.; Pavlović, M.; Radenović, S. Contractive conditions in b-metric spaces. Vojnoteh. Tech. Cour. 2017, 65, 851-865.

23. Došenović, T.; Radenović, S. Ansari's method in generalizations of some results in fixed point theory: Survey. Vojnoteh. Glas. Tech. Cour. 2018, 66, 261-268. [CrossRef]

24. Dung, N.V.; Hang, V.T.L. On the completion of b-metric spaces. Bull. Aust. Math. Soc. 2018. [CrossRef]

25. Huang, H.; Vujaković, J.; Radenović, S. A note on common fixed point theorems for isotone increasing mappings in ordered b-metric spaces. J. Nonlinear Sci. Appl. 2015, 8, 808-815. [CrossRef]

26. Hegedus, M. A New Generalization of Banach's Contraction Principle and Some Fixed Point Theorems in Metric Spaces; DM 78, 4; Karl Marx University of Economics: Budapest, Hungary, 1978.

27. Huang, H.; Deng, G.; Radenović, S. Fixed point theorems in $b$-metric spaces with applications to differential equations. J. Fixed Point Theory Appl. 2018, 20, 52. [CrossRef]

28. Jovanović, M.; Kadelburg, Z.; Radenović, S. Common fixed point results in metric-type spaces. Fixed Point Theory Appl. 2010, 2010, 978121. [CrossRef]

29. Kir, M.; Kiziltunc, H. On Some Well Known Fixed Point Theorems in b-Metric Spaces. Turk. J. Anal. Number Theory 2013, 1, 13-16. [CrossRef]

30. Karapinar, E. A Short Survey on the Recent Fixed Point Results on b-metric Spaces. Construct. Math. Anal. 2018, 1, 15-44. [CrossRef]

31. Mustafa, Z.; Jaradat, M.M.M.; Aydi, H.; Alrhayyel, A. Some common fixed points of six mappings on $G_{b^{-}}$ metric spaces using (E.A) property. Eur. J. Pure Appl. Math. 2018, 11, 90-109. [CrossRef]

32. Ozturk, V.; Turkoglu, D. Common fixed point theorems for mappings satisfying (E:A)-property in $b$-metric spaces. J. Nonlinear Sci. Appl. 2015, 8, 1127-1133. [CrossRef]

33. Ozturk, V.; Radenović, S. Some remarks on b-(E.A)-property in b-metric spaces. Springer Plus 2016, 5, 544. [CrossRef] [PubMed]

34. Ozturk, V.; Turkoglu, D. Fixed points for generalized contractions in $b$-metric spaces. J. Nonlinear Convers. Anal. 2015, 16, 2059-2066.

35. Pant, R.; Panicker, R. Geraghty and Ćirić's type fixed point theorems in b-metric spaces. J. Nonlinear Sci. Appl. 2016, 9, 5741-5755. [CrossRef]

36. Radenović, S.; Došenović, T.; Lampert, T.A.; Golubović, Z. A note on some recent fixed point results for cyclic contractions in $b$-metric spaces and an application to integral equations. Appl. Math. Comput. 2016, 273, 155-164. [CrossRef]

37. Radenović, S.; Došenović, T.; Osturk, V.; Dolićanin, Ć. A note on the paper: Integral equations with new admisibility types in $b$-metric spaces. J. Fixed Point Theory Appl. 2017, 10, 1007. [CrossRef]

38. Sintunavarat, W. Nonlinear integral equations with new admissibility types in $b$-metric spaces. J. Fixed Point Theory Appl. 2016, 18, 397-416. [CrossRef]

39. Samet, B.; Vetro, C.; Vetro, P. Fixed point theorems for $\alpha-\psi$-contractive type mappings. Nonlinear Anal. 2012, 75, 2154-2165. [CrossRef] 
40. Karapinar, E.; Kumam, P.; Salimi, P. On $\alpha-\psi$-Meir-Keeler Contract. Mappings. Fixed Point Theory Appl. 2013, 2013, 94. [CrossRef]

41. Chandok, S. Some fixed point theorems for $(\alpha, \beta)$-admissible Geraghty type contractive mappings and related results. Math. Sci. 2015, 9, 127-135. [CrossRef]

(c)

(C) 2019 by the authors. Licensee MDPI, Basel, Switzerland. This article is an open access article distributed under the terms and conditions of the Creative Commons Attribution (CC BY) license (http:/ / creativecommons.org/licenses/by/4.0/). 